\title{
The Role of Health Inequality in the Maternal Health Services Provided by Public Institutions in Mexico
}

\author{
Graciela Freyermuth-Enciso1, Mónica Carrasco-Gómez², Martín Romero-Martínez ${ }^{3}$ \\ ${ }^{1}$ Centro de Investigaciones y Estudios Superiores en Antropología Social (CIESAS) sede SURESTE, San Cristóbal \\ de las Casas, México \\ ${ }^{2}$ Cátedras CONACYT/Centro de Investigaciones y Estudios Superiores en Antropología Social sede SURESTE, San \\ Cristóbal de las Casas, México \\ ${ }^{3}$ National Public Health Institute's Research Center in Evaluations and Surveys, Cuernavaca, México \\ Email: gracielafreyermuth54@hotmail.com, lazulblues@yahoo.com.mx,martin.romero@insp.mx
}

Received 17 December 2015; accepted 2 February 2016; published 5 February 2016

Copyright (C) 2016 by authors and Scientific Research Publishing Inc.

This work is licensed under the Creative Commons Attribution International License (CC BY). http://creativecommons.org/licenses/by/4.0/

(c) (i) Open Access

\section{Abstract}

This work aims to determine the role of inequality in the provision of maternal health services among five regions in Mexico (northwest, northeast, central, the Mexico City-State of Mexico region and the south). We consider the most important service providers corresponding to the main health institutions in Mexico (IMSS, ISSSTE, SESAS, IMSS-Oportunidades). Therefore, a cross-sectional prospective study was conducted to analyze eight intervention packages (Prenatal Care, Syphilis, Influenza, Obstetric Urgent Care, HIV in pregnancy, delivery care, neonatal care and accessibility) offered by the Maternal and Perinatal Health (MPH) program. A quantitative analysis demonstrates low to marginal performance of the MPH program in three regions (South, Mexico City-State of Mexico and the Northwest) and marginal in two other regions (Central and Northeast). Furthermore, four of the intervention packages presented the lowest performance in the South (Prenatal Care, Syphilis, Influenza and Obstetric Urgent Care), as did the average of the total of the MPH packages. The performance of HIV in Pregnancy package was marginal in the Southern and Mexico City-State of Mexico regions and Neonatal Care was low in the Northwest. The assessment of the MPH intervention packages allows us to identify their strengths and weaknesses. This information allows us to identify similarities and differences among the geographical regions in order to describe and analyze the strengths, weaknesses, opportunities and threats in the current system and hence to improve the decision making regarding the Maternal and Perinatal Health Programs in Mexico. The results suggest that a homogenization has taken place in terms of the low quality of the services. 


\section{Keywords}

\section{Health Inequality, Evaluation of Health Services, Maternal and Perinatal Health, Quality of Care}

\section{Introduction}

The public health system in Mexico has been segmented through institutions that provide social security to different users (i.e., patients) according to their work assignment and also to those who lacked affiliation to a social security institution. Therefore, until the beginning of XXI century the health care services for the Mexicans were differential for population with social security (attended by IMSS and ISSSTE) and without social security who were attended by the Health Secretary and the IMSS-Oportunidades. López Acuña (1986) pointed out the inequalities in the health spending and the resources available for health care in Mexico [1].

In recent decades, we have witnessed structural changes in the organization of the Mexican health system, which have been influenced by international organizations and multilateral agencies of cooperation. The latter has been reflected in public policies and programs in order to strengthen local systems of health and to reduce the gaps among different geographical regions.

The aim of this article is to assess if public health policy focused on maternal and perinatal health in the 19802010 period has contributed to reducing inequality of care within different geographical regions in Mexico. An overview of the political context and the changes that have been promoted through the decentralization of health services since the eighties is presented in Section 2. Then, the methodology employed in this work is described (Section 3). An assessment on the performance of services in the five geographical regions of the country through the analysis of intervention packages in the four major public institutions is presented in Section 4. Finally, discussion and conclusions are presented in Sections 5 and 6, respectively.

\section{Background of the Decentralization of Health Services in Mexico}

Public policies have been created in Mexico to strengthen the governance of the health system as well as decrease inequalities among regions and institutions since the 1980s. The purpose of Mexico's health system, its governance, financing, and provision of services has been changing over the past three decades. These changes have been made based on studies that propose more efficient ways to administer resources in order to provide health care coverage to the Mexican population. These include deconcentration (1984), decentralization (1996), universal coverage (1994), universal insurance "Seguro Popular" (2003), and more recently the functional integration of the health system (2011) [2]-[4].

In 1981, President López Portillo implemented a series of health measures that established the basis for this new reform, which was aimed at providing coverage for the entire population [5]. For instance, the Department of Health Services (Coordinación para los Servicios de Salud) was created in order to develop normative, administrative, financial and technical guidelines which soon thereafter made it possible to integrate public health services under the National Health System. Decrees issued in 1983 and 1984 aimed to establish the basis for the decentralization of the Secretary of Public Education, Secretary of Agrarian Reform and the Secretary of Health and Welfare (SSA, Spanish acronym) [6] [7]. This first decentralization phase was supported not only by the Presidency of the Republic but also by the World Health Organization (WHO) [5]. By 1986, the states were expected to have consolidated their own health systems by establishing their health laws and decentralizing services for the general population without social security.

One problem that arose from the decentralization process was the heterogeneity of the conditions in the health sectors in each state, as well as the need to strengthen services before decentralizing them. Cardozo Brum and González Block et al. (cited by Homedes, 2008) [8] found that the states that decentralized services were wealthier, had a greater capacity to provide services to the uninsured population and had the support of the governor at that time; although they also had little infrastructure from the IMSS-Coplamar [9] [10]. During this stage decentralization was implemented in 14 states from 32.

Nevertheless, the process was interrupted due to lack of experience of decentralized states and/or the economic crisis in the country that took place the second half of the 1980s. The latter was accompanied by cuts in 
the health budget from $2.5 \%$ to $1.3 \%$ in the percentage of the gross domestic product allocated to health care and social security between 1980 and 1988 [11]. By the end of the 1980s, a process to modernize health services was initiated during President Salinas' administration (1988-1994), which was said to be a continuation of the plan presented by the previous government. The first agreement with the World Bank was also reached during this government's term, which was aimed at expanding the coverage of services in those states with problems in health care services. This established the foundation to strengthen the infrastructure in states with the greatest deficiencies in health services and infrastructure. Moreover, the institutional capacities of the states were promoted by decentralizing the acquisition of basic supplies and improving capacities to manage information systems.

During 1995-2000 period, the National Development Plan called for a new federalism to emerge out of the recognition of autonomous spaces in political communities and the respect for the various powers ascribed to each level of government. The aim was to harmoniously and effectively bring together the sovereignty of states and municipalities with the constitutional powers of the federal government. This was also intended to promote social participation and to define a new framework for relationships between the State and its citizens and organizations [12]. It was the 1996 National Accord ${ }^{1}$ that gave a new impetus to the decentralization process [13] and agreements between the federation and the states were signed, the last of which was by Chihuahua in February of 1999 [8].

Previous studies [14]-[16] pointed out that the majority of Latin American countries were pressured to reform health services, and one of the components of this reform was decentralization. The promoters of these initiatives were the World Bank, the Inter-American Development Bank and certain bilateral and multilateral development agencies. They proposed decentralization as part of a structural adjustment that would make it possible to free up federal resources to pay external debts. Decentralization would also facilitate the privatization of the health system, which is considered by neoliberal theory to be more efficient than public services (Collins 1989; Griffin, 1999; Ugalde and Homedes N. 2002).

It was believed that decentralization would facilitate a more reasonable and equitable distribution of the federal expenditures on health by taking into account mortality and marginalization indicators. It was also considered as a way to help balance per capita expenditures on health, thereby increasing both efficiency and equity. The decentralization process included the state governments' creation of legislative initiatives, or creation decrees, the formation of a government entity and the administration of federal resources through the SSA and the state governments. In turn, the SSA would decentralize the operations of health services from the federal to the state level and stipulate the priorities to be followed by the decentralized agencies. The SSA would also grant programming and budgeting functions to the states according to established federal guidelines [17].

Decentralization made it possible to allocate funds to the states in a more equitable manner. Thus, income improved for state governments with fewer resources. In terms of programming, the most important policies continued to be generated by the federal government but without the control mechanisms needed for them to be carried out in the states.

In 2003 during Vicente Fox’s term (2000-2006) the Social Health Protection System (Sistema de Protección Social en Salud; SPSS, Spanish acronym) and Seguro Popular de Salud (its operational arm) were approved in order to create medical insurance for the population without social security, through the reform of the General Health Law (Ley General de Salud; LGS Spanish acronym). Similar to enrollees in the IMSS and the ISSSTE, the SPSS is a financial instrument aimed at providing a per capita amount to Seguro Popular enrollees. This would standardize the financial structure of these three insurance systems.

The purpose of these reforms were to provide universal coverage for Mexicans through medical insurance with a financial structure similar to that of social security, in order to advance the functional integration of the health system.

The Health Sector Program (Programa Sectorial de Salud; PROSESA) was established in the 1980s to maintain the regulatory role of the Secretary of Health, consolidate the National Health System (SNS, Spanish acronym) and guarantee mechanisms to implement the right to health protection. PROSESA has 13 substantive programs and 3 support programs, including maternal and child health. This program was consolidate in accordance with Mexican Official Norm NOM-007-SSA2-1993 which was established by the federal government and

\footnotetext{
${ }^{1}$ National Agreement for the decentralization of health services, Journal of the Federation (DOF, Spanish acronym), September 25, 1996.
} 
stipulates the criteria for treating and monitoring women's health during pregnancy, delivery and the postnatal period, as well as for newborn care.

This program was created through the implementation of Seguro Popular, which has treated the population without social security since 2004, and at that time provided access to 20 interventions for maternal and child health. Additional initiatives were developed in 2008 and 2009 to decrease economic barriers and thereby improve access: 1) Healthy Pregnancy (Embarazo Saludable) which enabled pregnant women and their families to affiliate and 2) General Agreement on Inter-institutional Collaboration for Obstetric Emergency Care which established treatment for all women experiencing obstetric complications regardless of their affiliation in any of the health institutes (IMSS, ISSSTE or State Health Services [SESA]).

Nevertheless, at both the IMSS and the ISSSTE (institutions coordinated at the federal level, that is, they are not decentralized) maternal health care is based on prenatal health services at the primary level and delivery care at the secondary level, while obstetric emergencies are treated only at the secondary level where the timely treatment of obstetric emergencies and the public health perspective of the The Maternal and Perinatal Health Program (MPH) are not included in their guidelines. However, some of the components of the IMSS-O program are similar to the MPH, such as the organization of social community networks to transport the women and even community promoters to identify risks among pregnant women [18].

This article is focused on describing the availability of the interventions established by the regulations. It includes the four largest public and social security institutions in the country (IMSS, ISSSTE, SESAS, IMSSOportunidades) and encompasses five regions in Mexico (northwest, northeast, central, the Mexico City-State of Mexico region and the south) (See Table 1). This will allow us to identify similarities and differences among the regions in order to describe and analyze the strengths, weaknesses, opportunities and threats in the system and thereby suggest improvements that will ensure that the goods and services established by the regulations are provided in the various regions and health care subsystems.

\section{Methodology}

A cross-sectional prospective study was conducted using quantitative research methods. The Maternal and Perinatal Health Program was analyzed based on guidelines by the maternal and perinatal program, the Official Mexican Norms (Normas Oficiales Mexicanas; NOM, Spanish acronym), and clinical practice guidelines (CPG). Intervention packages were defined which were composed of a set of the marginal essential interventions needed for the adequate provision of services [19].

\subsection{Instruments}

Four instruments were designed to collect the information: 1) checklists, 2) questionnaires, 3) observation guides, and 4) interview guides to obtain information from the various actors. Nineteen areas were also defined to collect information, with specific informants at each establishment and according to level of care. The instruments were adapted and validated based on consensus with those responsible for the programs at each institution.

Eight health care packages covering a total of 134 primary level and 164 hospital level interventions were defined for the maternal and perinatal program²: 1) Accessibility: knowledge of the health care staff and population about the Healthy Pregnancy strategy (Embarazo Saludable) and the General Agreement on Inter-institutional Collaboration for Obstetric Emergency Care (Convenio General de Colaboración Interinstitucional para la Atención de Emergencias Obstétricas) as well as no physical, economic and cultural barriers to accessing health facilities; 2) Prenatal care: interventions aimed at identifying the skills and competencies needed to treat urinary infections and to determine risk factors for preeclampsia and hemorrhage. Other packages that represent some of the new challenges in prenatal care were included separately, such as the next three; 3) HIV-STI in Pregnancy: universal access to antiretroviral medication, adequate prevention campaigns and prevention of vertical transmission; 4) Syphilis: resources needed to perform the VDRL blood test for syphilis as well as early treatment; 5) Influenza in Pregnancy: early detection of cases, detection of complications and case referrals, adequate treatment, sufficient and adequate information aimed at the general public; 6) Delivery Care: a) the availability of supplies and instruments, b) the basic knowledge needed to provide medical attention as indicated by norms and

\footnotetext{
${ }^{2}$ These can be consulted in-depth in the technical report.
} 
Table 1. Evaluation of the performance of intervention packages, by region.

\begin{tabular}{|c|c|c|c|c|c|c|}
\hline \multirow{2}{*}{ Intervention Package } & \multicolumn{6}{|c|}{ Significance Tests by Region } \\
\hline & Northwest & Northeast & Central & MexCty-St of Mex & South & Overall Significance \\
\hline Mean for prenatal Care: & 0.6834 & 0.7236 & 0.6959 & 0.7127 & 0.5979 & \multirow{6}{*}{$0.000^{* * *}$} \\
\hline Northwest & & 0.277 & 0.662 & 0.512 & $0.003^{* * *}$ & \\
\hline Northeast & & & 0.247 & 0.776 & $0.000^{* * *}$ & \\
\hline Central & & & & 0.572 & $0.000^{* * *}$ & \\
\hline MexCty-St of Mex & & & & & $0.000^{* * *}$ & \\
\hline \multicolumn{6}{|l|}{ South } & \\
\hline Mean for HIV in Pregnancy: & 0.5223 & 0.7197 & 0.6447 & 0.5052 & 0.5304 & \multirow{6}{*}{$0.001^{* * *}$} \\
\hline Northwest & & $0.005^{* * *}$ & $0.053^{*}$ & 0.814 & 0.858 & \\
\hline Northeast & & & 0.235 & $0.003^{* * *}$ & $0.000^{* * *}$ & \\
\hline Central & & & & $0.041^{* *}$ & $0.007^{* * *}$ & \\
\hline MexCty-St of Mex & & & & & 0.563 & \\
\hline \multicolumn{6}{|l|}{ South } & \\
\hline Mean for Syphilis: & 0.5782 & 0.6426 & 0.3966 & 0.5019 & 0.3744 & \multirow{6}{*}{$0.000^{* * *}$} \\
\hline Northwest & & 0.136 & $0.000^{* * *}$ & $0.100^{*}$ & $0.000^{* * *}$ & \\
\hline Northeast & & & $0.000^{* * * *}$ & $0.004^{* * *}$ & $0.000^{* * *}$ & \\
\hline Central & & & & $0.005^{* * *}$ & 0.439 & \\
\hline MexCty-St of Mex & & & & & $0.002^{* * * *}$ & \\
\hline \multicolumn{6}{|l|}{ South } & \\
\hline Mean for influenza: & 0.5221 & 0.684 & 0.5508 & 0.4499 & 0.4068 & \multirow{6}{*}{$0.000^{* * *}$} \\
\hline Northwest & & $0.007^{* * *}$ & 0.601 & 0.331 & $0.038^{* *}$ & \\
\hline Northeast & & & $0.001^{* * *}$ & $0.000^{* * *}$ & $0.000^{* * *}$ & \\
\hline Central & & & & $0.051^{*}$ & $0.001^{* * *}$ & \\
\hline MexCty-St of Mex & & & & & 0.442 & \\
\hline \multicolumn{6}{|l|}{ South } & \\
\hline Mean for delivery care: & 0.6911 & 0.7887 & 0.7415 & 0.747 & 0.7012 & \multirow{6}{*}{0.582} \\
\hline Northwest & & 0.365 & 0.496 & 0.496 & 0.783 & \\
\hline Northeast & & & 0.646 & 0.721 & $0.094^{*}$ & \\
\hline Central & & & & 0.948 & 0.3 & \\
\hline MexCty-St of Mex & & & & & 0.284 & \\
\hline South & & & & & & \\
\hline Mean for neonatal care: & 0.4853 & 0.6645 & 0.7742 & 0.7819 & 0.6074 & \multirow{6}{*}{0.099} \\
\hline Northwest & & 0.41 & $0.072^{*}$ & $0.046^{* *}$ & 0.28 & \\
\hline Northeast & & & 0.434 & 0.454 & 0.697 & \\
\hline Central & & & & 0.943 & 0.13 & \\
\hline MexCty-St of Mex & & & & & $0.068^{*}$ & \\
\hline South & & & & & & \\
\hline
\end{tabular}




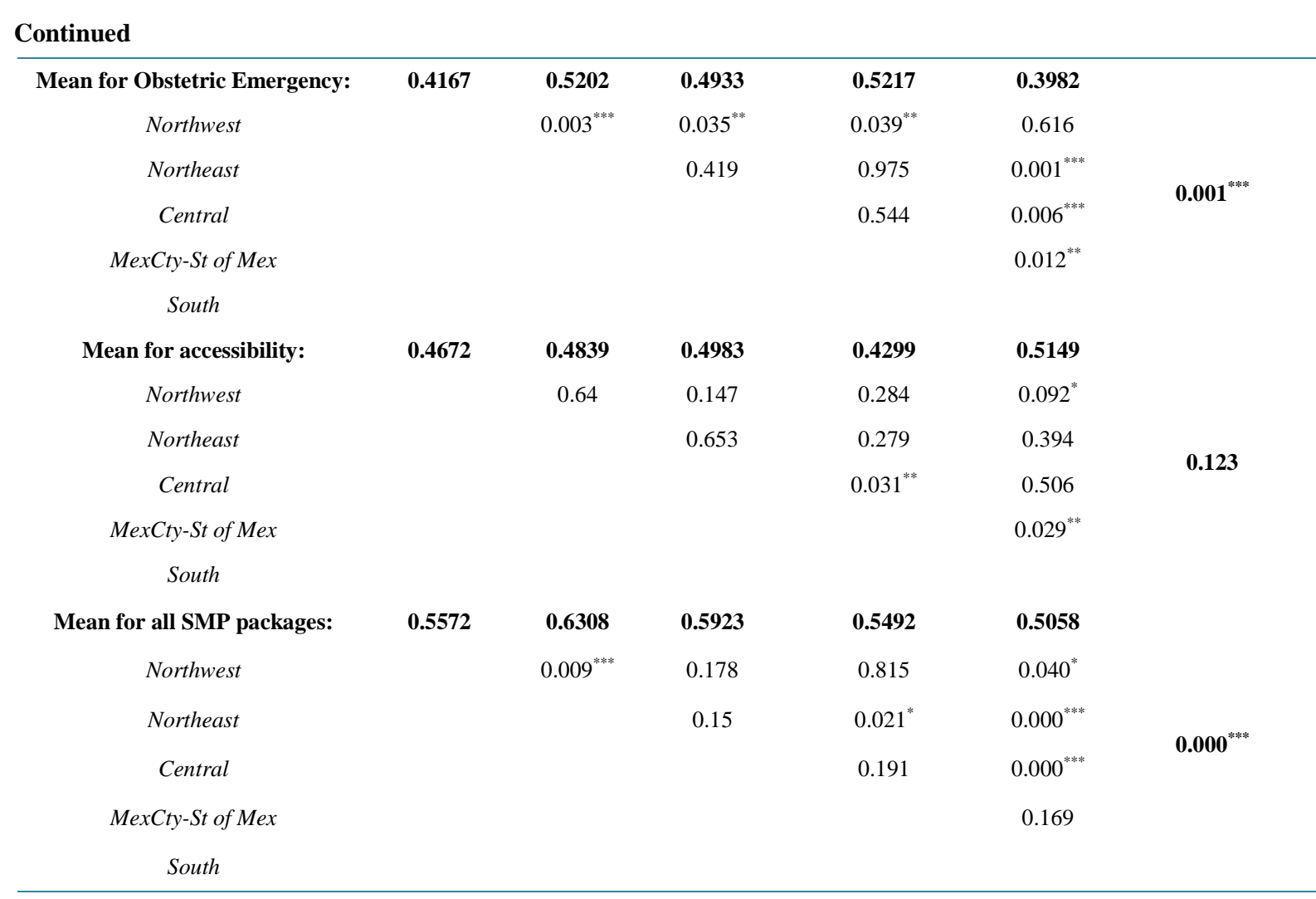

Significance ${ }^{* * *} \mathrm{p}$ value $\leq 0.01,{ }^{* *} \mathrm{p} \leq 0.05,{ }^{*} \mathrm{p} \leq 0.10$.

to ensure adequate care and the privacy and comfort of the mothers, c) the availability of checkups and monitoring procedures to ensure the early detection of complications); 7) Neonatal Care: interventions that help to identify the neonate's availability to receive checkups (those born with and without complications) and the availability of supplies and strategies for the screening and early detection of hypothyroidism; and 8) Obstetric Emergency Care: the availability of the instruments, supplies and knowledge that enable the physician to make decisions related to the most common obstetric emergencies and the availability of medications to treat those problems.

\subsection{Sampling Methods}

The sampling framework was dictated by the health sector national directory of health care facilities (http://clues.salud.gob.mx/). Stratified and clustered sampling methods were used. Five regions were defined (as described in Figure 1) and 10 municipalities were chosen from each region. The facilities were selected with probability proportional to the population of the municipality. In each municipality, one medical establishment was selected for each one of eight strata defined by institution criteria (IMSS, IMSS-Prospera, ISSSTE, SESA) and type of establishment (primary care and hospitalization).

The medical establishments were selected with probability proportional to their size, defined as the inverse square root of the frequency of their typology, as presented by the SSA webpage (http://clues.salud.gob.mx/).

Each unit in the sample was then assigned a weight ( $w$ ) based on the selection probability. The directory of national medical establishments in the health sector provided by the SSA webpage (http://clues.salud.gob.mx/) was used as the sampling framework.

The sample was composed of 205 medical units, 50 municipalities and 23 states and Mexico City. Responses were obtained from 201 medical units ( $2 \%$ non-response). The sample size was defined based on a study of the performance of maternal services and was nationally representative of institutions providing these services and the types of populations they treat.

The fieldwork was conducted from September to December 2010. The CSPro Census and Survey Processing System (www.census.gov/population/international/software/cspro/) was used for the data entry. 


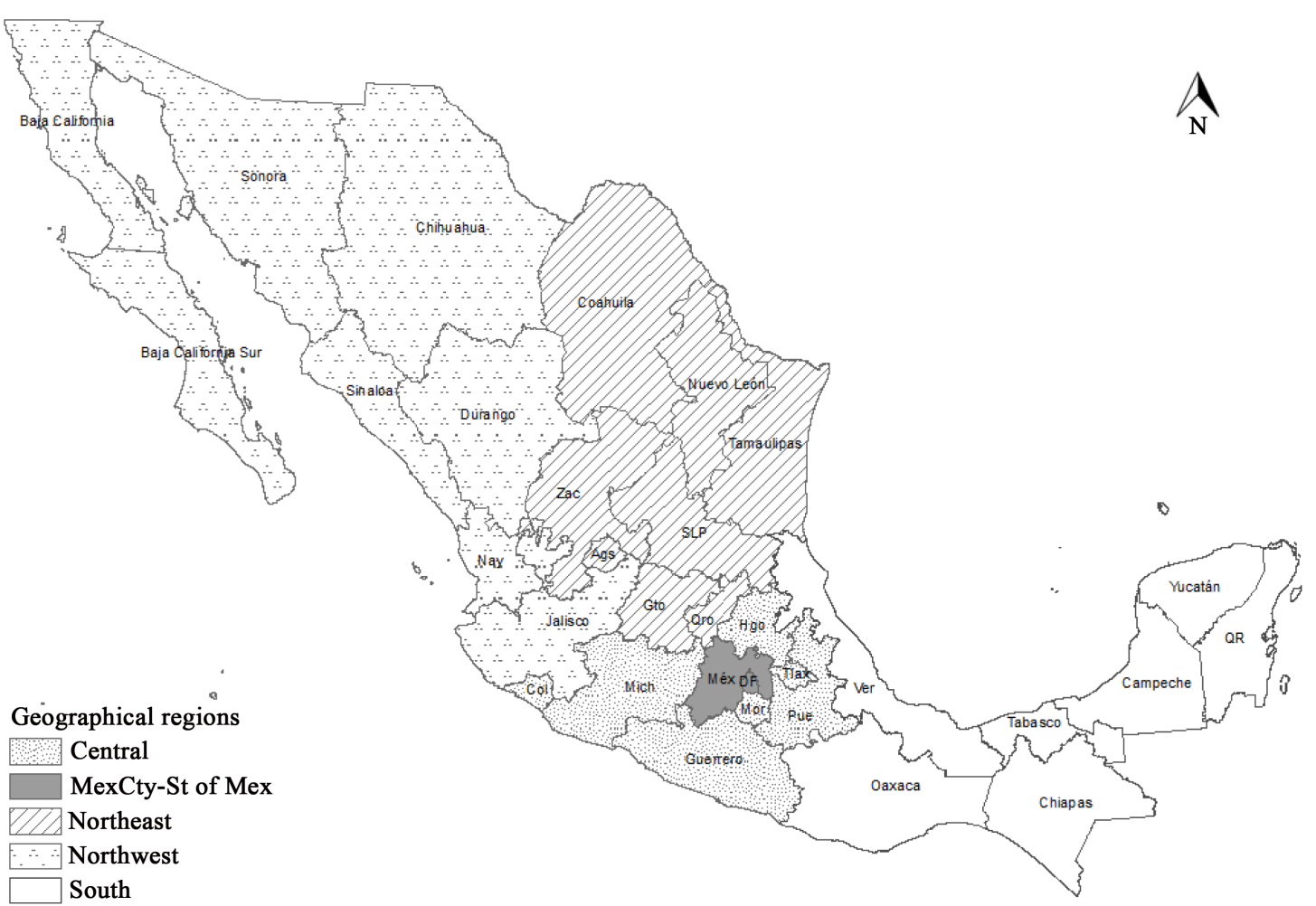

Figure 1. Regional distribution of the states.

\subsection{Data Analysis}

The scores for each region were estimated for each of the intervention packages (Prenatal Care, Syphilis, Influenza, Obstetric Urgent Care, HIV in pregnancy, delivery care, neonatal care and accessibility). The intervention packages were evaluated using indices that represented a relative score with respect to the total items evaluated, according to the services provided by each unit. This was obtained by calculating the quotient of the sum of points accumulated by a medical unit divided by the number of items evaluated in that unit (minimum value $=$ 0 and maximum value =1). A detailed description of this analysis can be found in Freyermuth et al. (2011) [18].

Two levels of analyses were performed. The first consists on a statistical, significance test for a regional comparison of the indices through the obtainment of the T-Student ${ }^{3}$ test considering the design effect, since the primary units in the sample were the municipalities and not the medical units. All of the T-Student test were run but only tests that were significant for a level of .01 were discussed. The second level of analysis was qualitative, through the traffic light system described above, which explored the deficiencies in the contents of the intervention packages in order to drive public policies. The performance scale proposed by the National Council for the Evaluation of Social Policy (Consejo Nacional de Evaluación de la Política de Desarrollo Social; CONEVAL, Spanish acronym) was used to create a traffic light system based on the indices. A score equal to or more than 0.85 was an indicator of good performance, 0.70 to 0.84 adequate performance, 0.50 to 0.69 marginal performance and low performance is indicated by values under 0.50 .

This research was approved by the ISSSTE Research Ethics Committee and written consent to conduct the evaluation was obtained from each institution. The confidentiality of the participants was maintained.

\section{Results}

\subsection{Performance of the MPH Program}

The mean index for the program was 0.56 (95\%CI; 0.48, 0.64), which can be interpreted as the middle value.

${ }^{3}$ The T-student is computed as $\mathrm{t}=(\mathrm{x}-\mathrm{y}) / \mathrm{sqr}(\operatorname{Var}(\mathrm{x}-\mathrm{y}))$ where $\mathrm{x}$ and $\mathrm{y}$ are mean scores of different programs and $\operatorname{Var}()$ is estimated taking into account the sampling design. 
This is noteworthy since it is one of the oldest programs provided by public health institutions. According to confidence levels, its performance was low to marginal in three regions (South (with a mean of .50), MexCty-St of Mex and the Northwest) and marginal in two regions (Central and Northeast). Significant differences in the performance of the entire set of packages in the SMP program were found when comparing the South to three other regions (Northeast, Northwest and Central). Also noteworthy is that the MexCty-St of Mex region was not one of the regions with better performance in the provision of this type of service. No differences were found between this region and the South and the performance in both MexCty-St of Mex and the Northwest was significantly lower than in the Northeast. The order of how well this program performed was: Northeast, Central, Northwest, MexCty-St of Mex and South.

Furthermore, four of the eight packages had the lowest performance in the South (Prenatal Care, Syphilis, Influenza and Obstetric Urgent Care), as did the average of the total of the MPH packages. HIV in Pregnancy had marginal performance in the South and the MexCty-St of Mex region and Neonatal Care had low performance in the Northwest. Although no significant differences were found among regions for three packages (delivery care, newborn care and accessibility), we describe them based on the second level of analysis which is aimed at establishing a performance range for the intervention packages and monitoring the components of the program.

\subsection{Overall Performance of the Intervention Packages in the MPH Program}

In the provision of services related to delivery care, which can be considered to be a traditional maternal-infant care service, adequate performance was found with no significant differences among regions. Furthermore, other traditional intervention packages exist, such as prenatal care which resulted in indices of $0.68,0.72,0.70,0.71$ and 0.60 in the Northwest, Northeast, Central, MexCty-St of Mex and Southern regions, respectively, indicating marginal and adequate performance. In the case of neonatal services, the average indices were $0.49,0.66,0.77$, 0.78 and 0.60 in the above regions, respectively. Thus the extremes were the Northwest with very low performance and the Central and MexCty-St of Mex regions with adequate performance. Nevertheless, it is worth mentioning that the South was notable for having the lowest prenatal care performance index of all the regions.

Obstetric Emergency Care is one of the intervention packages recently implemented in the health sector, which was established in 2006. This package resulted in low performance in the Northwest (0.47), Central (0.49) and especially the South (0.39) and marginal performance in the Northeast and the MexCty-St of Mex regions (0.52).

In terms of prenatal care, the interventions that determined its marginal performance in three of the regions were knowledge about high-risk factors for preeclampsia and about medications indicated for urinary infections during pregnancy. At the hospital level, interventions classified as low performance were also related to a lack of knowledge about detecting risk factors for preeclampsia and treating urinary infections, as well as a failure to indicate to women at their first prenatal checkup (at 24 weeks gestation) the laboratory tests to be performed. Nevertheless, the other interventions presented adequate performance, as mentioned previously, indicating that the prevention of neural tube problems and the availability of supplies for their prevention were adequate for interventions related to the health of the baby.

As mentioned previously, delivery care was the package which presented adequate performance in four of the five regions, with no differences among the regions. This demonstrates the availability of supplies and equipment, having basic knowledge about the medical care indicated in the NOM-007, and the availability of checkups and monitoring procedures to ensure the early detection of complications. Nevertheless, some of the individual interventions resulted in low performance in all of the regions, including insufficient walking space in delivery rooms for women in labor and a lack of partograms (except in MexCty-St of Mex and the Northwest). In the $\mathrm{CE}^{4}$, there was a lack of oxytocin in the Northwest and Central regions and both oxytocin and ergonovine in MexCty-St of Mex, which compromises women's comfort and puts their lives in risk because of hemorrhage.

For neonatal care, adequate performance was found in the Central and MexCty-St of Mex regions, marginal in the South and Northeast and low in the Northwest. This indicates the need to improve the immediate care of neonates by providing interventions that guarantee the treatment of complications, the provision of supplies and strategies for the screening and early detection of hypothyroidism. The interventions with the lowest indices in all the regions were the lack of medical certificates, neonatal resuscitation equipment and Silverman Anderson and Apgar evaluation tables.

\footnotetext{
${ }^{4} \mathrm{CE}$ refers to the Rural Medical Units run by the IMSS-Oportunidades program and Health Centers that provide hospitalization for primary care delivery.
} 
Regarding of Obstetric Emergency care, marginal performance was found only in the Northeast and MexCty-St of Mex regions. Performance was low in the other regions and the South had the lowest average index (0.39), where medical staff did not have the competencies needed to make decisions about the most common obstetric emergencies, such as what to do in case of hemorrhaging and toxemia and risk factors for postpartum hemorrhaging. Medications to treat these problems were lacking as well as manuals and algorithms related to obstetric hemorrhage, sepsis and miscarriage. In terms of supplies, plasma expanders, cephalexin and gentamicina were not available or free substitutes were not provided. There was also an inability to perform blood cultures, urine cultures and antibiograms, as well as to identify serum lactate. In addition, ultrasounds were not available 24 hours per day 7 days per week for emergencies.

Intervention packages for prenatal care that have been recently and systematically more implemented include the detection and treatment of HIV-AIDS and syphilis and the prevention of influenza in pregnant women. In the case of HIV detection, interventions related to checkups and early treatment for women who test positive as well as measures to prevent vertical transmission performed adequately in the Northeast and had marginal performance in the other four regions. The main weaknesses in this package were: not offering the rapid HIV test to all pregnant women; deficiency in availability of rapid tests for HIV; lack of informed consent forms for HIV diagnoses; lack of a guide for the use of rapid tests; laboratories without the capacity to perform viral load tests, TCD4 and TCD8 counts and western blot tests; and the unavailability of antiretroviral drugs, including HIV STI/zidovudine (AZT)+lamivudine (3tc)+lopinavir (saquinavir, ritonavir).

A similar situation was found for the influenza packages, which had marginal performance in the Northwest (0.52), Northeast (0.68) and Central (0.55) regions and low performance in MexCty-St of Mex (0.45) and the South (0.40). These differences in performance were primarily associated with the availability of treatment and the timely referral in the event of complications. The main deficiencies were: insufficient information related to recognizing and preventing the transmission of influenza; the absence of oseltamivir, zanamivir and the vaccine; and a lack of clinical guides for treatment and referrals as well as visible algorithms that facilitate diagnosis and treatment.

Even though it has been mandatory for decades, the intervention package to detect and treat syphilis was found to have low performance in the Central (0.39) and South (0.37) and marginal in the Northeast (0.68), Northwest (0.52) and MexCty-St of Mex (0.55) regions. The interventions identified as being most deficient were not performing VDRL syphilis detection tests and not having diagnostic and treatment guides or adequate dosages of medications such as penicillin G benzathine, ceftriaxone (500 mg) and azithromycin (500 mg).

Lastly, the performance of the accessibility package was low in four of the five regions and marginal only in the South, although the difference was not significant. This is important given that difficulties with access have been one of the main problems in the early treatment of obstetric emergencies. In 2010 when the information was collected, two strategies were implemented to improve universal coverage of the service and its functional integration Healthy Pregnancy (Embarazo Saludable) and the Inter-Institutional Agreement for Obstetric Emergency Care (Convenio Interinstitucional para la Atención de la Urgencia Obstétrica). Therefore, in addition to monitoring whether or not physical, economic and cultural barriers to the facilities existed, health care staff and the populations were also evaluated as to whether or not they knew about these strategies (free, support from health staff, ambulance service, telephone, etc.).

The low performance by the accessibility package was primarily due to not visibly displaying hours, lack of staff who spoke the local indigenous language, poor dissemination of information about the Healthy Pregnancy program and insufficient information about the signs and symptoms of obstetric emergencies. It is also worth mentioning that health care staff were not aware of the IMSS-ISSSTE-SESA agreement regarding obstetric emergency care and information was lacking about where to go for delivery care as well as about Seguro Popular and enrollment and complaint procedures.

\section{Discussion}

The proposed methodology contributes to rapidly identify interventions considered by the health sector to be essential to the performance of services. The methodology can be used to make synthetic comparisons, in this case among regions, as well as institutional comparisons among health care services and among medical units.

While in some ways decentralization tried to homogenize the regions' institutional capacities to produce services, in the case of maternal and perinatal services significant differences were found when comparing the 
Northwest, Northeast and Central regions with the South and the Northeast and MexCty-St of Mex regions, in which the MPH program performed lowest in the South. What is notable is a homogenization in the performance of regions with marginal to low indices. None of the intervention packages showed good performance and, at best, three of the eight packages studied had adequate performance in the Northeast and the MexCty-St of Mex region.

Although the differences among regions would be expected to range from good and adequate to marginal and low, the quality of maternal-infant services was found to be heterogeneous even within the same region. In addition, all regions had some intervention packages with low performance while most of the services were classified as marginal.

Homedes and Ugalde (2008) concluded that, 25 years after implementing decentralization in Mexico, inequalities in the health system have increased due to an unclear process and ineffective strategies to compensate for inequalities among the decentralized states. We suggest that while these inequalities have continued, the present study shows that the services generally tend to have marginal and low performance in all regions. Thus, not only has there been a failure to homogenize quality and decrease gaps, we consider these results to be more indicative of a homogenization in terms of the low quality of the service than of a deepening of inequalities.

While it is the case that low performance was found in the South for four of the eight intervention packages (Prenatal Care, Syphilis, Influenza, Obstetric Emergencies), the other four were found to have low performance in other regions. The performance of accessibility was low even in the Northeast, which had the highest quality ranking.

The "Evaluation of Women's Health Care Programs” presented results by level of care (primary and secondary) and by the type of population receiving the services (insured and uninsured). This evaluation found significant differences between the secondary level and insured population (IMSS/ISSSTE) as compared to the primary care level and uninsured population, in which the former had better performance. Nevertheless, a worrisome trend was found similar to that presented by the regional findings, in which there was low performance in the capacity to offer Obstetric Emergency Care, especially by institutions aimed at the uninsured population. Furthermore, although the performance of the IMSS/ISSSTE was classified as marginal, this also cannot be considered satisfactory [20].

Performance in the accessibility to the health system continues to be low, especially in terms of what the National Aboriginal Health Organization refers to as cultural security, which is understood as the capacity of service providers to communicate with patients according to their political, economic, social, spiritual and linguistic perspectives [21]. This has even been associated with resistance towards adhering to portions of the NOM-007, including adopting the position desired by the woman in labor [18], weaknesses in the infrastructure and placing furniture in such a way that makes it difficult for women to walk during labor. These infrastructure and supply problems have been recognized by the Mexican Collegiate Federation of Obstetrics and Gynecology (Federación Mexicana de Colegios de Obstetricia y Ginecología, A.C.; FEMECOG, Spanish acronym) ${ }^{5}$.

It is also important to mention that communication within institutions and among their own members was found to be insufficient and it was evident that primary- and secondary-level health care staff in MexCty-St of Mex and the Southern regions lacked knowledge about policy agreements to improve performance and access (such as the Inter-Institutional Agreement for Obstetric Emergency Care). This has also been reported in the states of Guerrero, Oaxaca and Veracruz [22].

The low performance evident in primary-level obstetric emergency care demonstrated little knowledge on the part of health care staff about protocols used to treat the most common causes of obstetric emergencies and a lack of guides to manage these emergencies and the supplies needed to treat them. In an evaluation of participatory actions related to the MPH program, the measures used to support obstetric emergencies had an influence on the availability of transportation and housing for pregnant women, which helped to obtain international certification of Arranque Parejo en la Vida actions [23]. This information could be compared to our findings, nevertheless while both studies refer to obstetric emergency care they do not evaluate the same actions.

At the hospital level, the low performance by the HIV package indicated deficiencies in the capacity to perform tests and in the availability of antiretroviral drugs, even though a strategy existed and resources were allocated [24]. Deficiencies were also identified in the influenza package, in spite of the severity of the epidemic

\footnotetext{
${ }^{5}$ We are referring to the announcement issued on June 10, 2015 about obstetric violence and legislative initiatives in some states, available in http://www.femecog.org.mx/docs/FEMECOG\%20pronunciamiento.pdf
} 
and its political visibility in 2009 [25]. Therefore, further research, monitoring by citizens and social accountability continue to be necessary not only to see whether the public resources allocated to the programs are being adequately distributed and used but also in order to design and create processes and indicators that evaluate their impacts [26].

In the South, specifically in the case of Chiapas, Freyermuth identified particular social and political situations as having contributed to a substantial increase in the health budget through the Ramo 33 Health Services Fund (Fondo de Aportaciones para los Servicios de Salud; FASSA, Spanish acronym) [6] such as the Zapatista uprising in 1994 and the decentralization of state services in 1998. While this could have signified an improvement in the performance of the services provided, it is important to note that deficiencies were found in the South, especially at the primary care level of the new programs (syphilis, influenza and obstetric emergency care programs).

In addition, even though the national SPSS budget increased over $600 \%{ }^{6}$ between 2004 and 2010, the IMSS and ISSSTE were the institutions that continued to show better performance.

Therefore, differences in performance among regions could be identified in spite of several attempts to improve the health system. These regional differences persisted even after performing interventions, increasing budgets and implementing programs to attempt to address the lack of coverage by decentralizing the National Health System and implementing Seguro Popular. And even after attempts to improve maternal-infant care by integrating the system through a variety of strategies, such as the Agreement, the 2006 Medical Insurance for a New Generation in 2006 and Healthy Pregnancy in 2009, it can be identified that there are different performances between regions. In this regard, it is important to mention that the region which presented the poorest performance was the South. This can be interpreted as a failure of the concentration of resources to bring about the short-term results expected and the need to ensure a more effective allocation of the budget and to target resources towards the most vulnerable populations.

This inequality has also been identified by recent studies focused on particular programs aimed at combating inequalities in municipalities with a lower human development index, which found that inequality increased [27]. Gwatkin and Ergo (2011) called this phenomenon "regressive universalization," in which programs aimed at universal coverage largely end up benefiting less disadvantaged populations to a greater degree than more vulnerable populations [28].

\section{Conclusions}

In this work, an assessment of the interventions in the SMP program allows us to identify their strengths and weaknesses. This analysis provided useful information for policy-makers and health program decision-makers in order to improve the provision of health services of pregnant women and neonates. Surprisingly, regions with the more important health care facilities (i.e., MexCty-St of Mex) presented low to marginal performance in the MPH program with similar scores to the poorest region (South). Four of the eight packages had the lowest performance in the South (Prenatal Care, Syphilis, Influenza and Obstetric Urgent Care), as did the average of the total of the SMP packages.

Despite preeclampsia being the second leading cause of maternal death in Mexico, the evaluation in the prenatal care package showed shortcomings in the knowledge about high-risk factors for preeclampsia and indicated medications for urinary infections during pregnancy. On the other hand, in delivery care, which can be considered to be a traditional maternal-infant care service, adequate performance was found with no significant differences among regions.

We suggest that while these inequalities have continued, the present study shows that the services generally tend to have marginal and low performance in all regions. These results suggest that a homogenization has taken place in terms of the low quality of the service than of a deepening of inequalities.

These monitoring exercises need to be continued at the academic level in order to evaluate the performance of maternal and neonatal programs, so as to identify progress and setbacks and suggest control measures. Lastly, the national health system needs to be strengthened so it can function as a single system operated with public financing.

\footnotetext{
${ }^{6}$ Comparison in constant pesos from the year 2004 to 2009 of the total budget allocated to the SPSS, with data from the SHCP from the years 2004 to 2008. From the federal treasury department account, 2009, PEF APROBADO (approved federal expense budget). Source: Diaz, D., Pérez, M. A. C., \& Navarro, S. M. (2010) p. 39.
} 


\section{Acknowledgements}

The authors want to acknowledge to the authorities of the Federal Ministry of Health, IMSS-Oportunidades IMSS, ISSSTE and state health services for the facilities provided in the implementation of this evaluation work. And, for their financial support, to the Women's National Institute (INMUJERES), CIESAS and Catedras program of CONACYT.

\section{References}

[1] López Acuña, D. (1986) La salud desigual en México. Siglo Veintiuno Editores, México.

[2] Londoño, J.L. and Frenk, J. (1997) Structured Pluralism: Towards an Innovative Model for Health System Reform in Latin America. Health Policy, 41,1-36. http://dx.doi.org/10.1016/S0168-8510(97)00010-9

[3] Soberón, G. and Valdéz, C. (2007) Evidencias y salud, ¿Hacia dónde va el sistema de salud en México? Salud Pública de México, 49, 5-27. http://dx.doi.org/10.1590/S0036-36342007000700002

[4] Secretary of Health (2011) Hacia la integración funcional del Sistema Nacional de Salud. Secretaría de Salud, México.

[5] Soberón-Acevedo, G. and Martínez-Narváez, G. (1996) La descentralización de los servicios de salud en México en la década de los ochenta. Salud Pública de México, 38, 371-378.

[6] Freyermuth Enciso, M.G., Sánchez Pérez, H. and Argüello Avendaño, H. (2015) Transparencia y rendición de cuentas en salud materna: El caso del AFASPE en Chiapas. Revista Pueblos y Fronteras, 9, 79-93. http://www.pueblosyfronteras.unam.mx/v09n17/05art.html

[7] Diario Oficial de la Federación (DOM) (1983) Decreto por el que el Ejecutivo Federal establece bases para el programa de descentralización de los Servicios de salud de la SECRETARÍA DE SALUBRIDAD Y ASISTENCIA. México. http://www.dof.gob.mx/nota to imagen fs.php?cod diario=207621\&pagina $=11 \&$ seccion=0

[8] Homedes Beguer, N. and Ugalde, A. (2008) 25 años de descentralizacion del sistema de salud mexicano: Una experiencia para analizar. Revista Gerencia y Políticas de Salud, 7, 26-43.

[9] Cardozo, M. (1993) Análisis de la política descentralizadora del sector salud: Centro de Investigación y Docencia Económicas. México, D.F.

[10] González Block, M.A., Leyva, R., Zapata, O., Loewe, R. and Alagón, J. (1989) Health Services Decentralization in México: Formulation, Implementation and Results of Policy. Health Policy and Planning, 4, 301-315. http://dx.doi.org/10.1093/heapol/4.4.301

[11] López Arellano, O. and Blanco Gil, J. (1993) La modernización neoliberal en salud: México en los ochenta. México Universidad Autónoma Metropolitana, México.

[12] Diario Oficial de la Federación (DOM) (1995) Plan Nacional de Desarrollo 1995-2000 (Separata), México. http://www.dof.gob.mx/nota detalle.php?codigo $=4874791 \&$ fecha $=31 / 05 / 1995$

[13] Sales Heredia, F.J. (2012) A 30 años de la descentralización de los servicios de salud. Centro de Estudios Sociales y de opinión Pública de la Cámara de Diputados, LX Legislatura. Documento de trabajo núm. 140.

[14] Collins, C.D. (1989) Decentralization and the Need for Political and Critical Analysis. Health Policy and Planning, 4, 168-171. http://dx.doi.org/10.1093/heapol/4.2.168

[15] Griffin, C. (1999) Empowering Mayors, Hospital Directors, or Patients? The Decentralization of Health Care. In: Burki, S.J., Perry, G. and Dillinger, W., Eds., Beyond the Center: Decentralizing the State, World Bank, Washington DC.

[16] Ugalde, A. and Homedes, N. (2002) Descentralización del sector salud en América Latina. Gaceta Sanitaria, 16, 1829. http://dx.doi.org/10.1016/S0213-9111(02)71629-4

[17] Escalante, E. (2000) El Ramo 33 Aportaciones Federales para Entidades Federativas y Municipios y Avances en el Federalismo. Crónica Legislativa. Cámara de Diputados LVIII Legislatura No. 12, México, 77-81. http://www.diputados.gob.mx/cronica57/contenido/cont12/leer8.html

[18] Freyermuth, G., et al. (2011) Monitoreo de la atención a las mujeres en servicios públicos del sector salud. Cuadernos de Trabajo 29, Instituto Nacional de las Mujeres-Centro de Investigaciones y Estudios Superiores en Antropología Social, México. http://www.inmujeres.gob.mx/images/stories/cuadernos/c29 o.pdf

[19] Oohna, C. and Graham, W. (2006) Strategies for Reducing Maternal Mortality: Getting on with What Works. The Lancet, 368, 1284-1299. http://dx.doi.org/10.1016/S0140-6736(06)69381-1

[20] Freyermuth Enciso, G., Meneses Navarro, S. and Romero Martínez, M. (2015) Evaluation of Women’s Health Care Programs in the Main Institutions of the Mexican Health System. Cadernos de Saúde Pública, 31, 71-81.

[21] National Aboriginal Health Organization (2008) Cultural Competency and Safety: A Guide for Health Care Administrators Providers and Educator. National Aboriginal Health Organization, Otawa. 
[22] Rodríguez Soriano, D., Freyermuth Enciso, M.G. and Argüello Avendaño, H. (2013) Monitoreos al acuerdo para el fortalecimiento de las acciones de salud pública en los estados y al convenio general de colaboración interinstitucional para la atención de la emergencia obstétrica. Un ejercicio de contraloría social. Observatorio de Mortalidad Materna en México.

http://www.omm.org.mx/images/stories/Documentos\%20grandes/ANA\%20Informe\%20integrado\%20AFASPE\%20C ONVENIO\%20AEO\%20VERSI\%C3\%93N\%20FINAL\%20mayo\%2016,\%202013-2.pdf

[23] Orozco-Nuñez, E., González-Block, M.A., Kageyama-Escobar, L.M. and Hernández-Prado, B. (2009) Participación social en salud: La experiencia del programa de salud materna Arranque Parejo en la Vida. Salud Pública de México, 51, 104-113. http://dx.doi.org/10.1590/S0036-36342009000200005

[24] Secretary of Health (2008) Programa de acción específico Arranque Parejo en la Vida, SSA, México.

[25] Torres Ramírez, A. (2010) La influenza pandémica A (H1N1) en mujeres embarazadas. Ginecología y Obstetricia de México, 78, 121-127.

[26] Freyermuth, G. and Sesia, P., Eds. (2013) Monitoreos, diagnósticos y evaluaciones en salud maternal y reproductiva: Nuevas experiencias de contraloría. Centro de Investigaciones y Estudios Superiores en Antropología Social/Comité Promotor por una Maternidad Segura-México, Observatorio de Muerte Materna-México.

[27] Meneses Navarro, S., González Block, M.A., Quezada Sánchez, A.D. and Freyermuth Enciso, G. (2014) Evolución de la equidad en el acceso a servicios hospitalarios según composición indígena municipal en Chiapas, México: 2001 a 2009. In: Page Pliego, J.T., Ed., Enfermedades del rezago y emergentes desde las ciencias sociales y la salud pública, Programa de Investigaciones Interdisciplinarias sobre Mesoamérica y el Sureste, Instituto de Investigaciones Antropológicas, Universidad Nacional Autónoma de México, México, 17-35.

[28] Gwatkin, D. and Ergo, A. (2011) Universal Health Coverage: Friend or Foe of Health Equity? The Lancet, 377, 21602161. http://dx.doi.org/10.1016/S0140-6736(10)62058-2 